\title{
Noninvasive in vivo fluorescence measurement of airway-surface liquid depth, salt concentration, and pH
}

\author{
Sujatha Jayaraman, Yuanlin Song, L. Vetrivel, Leena Shankar, and A.S. Verkman \\ Departments of Medicine and Physiology, Cardiovascular Research Institute, University of California, \\ San Francisco, California, USA \\ Address correspondence to: Alan S. Verkman, 1246 Health Sciences East Tower, Cardiovascular Research Institute, \\ University of California, San Francisco, California 94143-0521, USA. Phone: (415) 476-8530; Fax: (415) 665-3847; \\ E-mail: verkman@itsa.ucsf.edu; Website: http://www.ucsf.edu/verklab.
}

Received for publication August 26, 2000, and accepted in revised form December 19, 2000.

\begin{abstract}
The concentration of salt in the thin layer of fluid at the surface of large airways, the airway-surface liquid (ASL), is believed to be of central importance in airway physiology and in the pathophysiology of cystic fibrosis. Invasive sampling methods have yielded a wide range of ASL [ $\mathrm{NaCl}]$ from 40 to $180 \mathrm{mM}$. We have developed novel fluorescent probes and microscopy methods to measure ASL thickness, salt concentration, and $\mathrm{pH}$ quantitatively in cell-culture models and in the trachea in vivo. By rapid z-scanning confocal microscopy, ASL thickness was $21 \pm 4 \mu \mathrm{m}$ in well-differentiated cultures of bovine tracheal epithelial cells grown on porous supports at an air-liquid interface. By ratio imaging fluorescence microscopy using sodium, chloride, and $\mathrm{pH}$-sensitive fluorescent indicators, ASL $\left[\mathrm{Na}^{+}\right]$was $97 \pm 5 \mathrm{mM},\left[\mathrm{Cl}^{-}\right]$was $118 \pm 3 \mathrm{mM}$, and $\mathrm{pH}$ was $6.94 \pm 0.03$. In anesthetized mice in which a transparent window was created in the trachea, ASL thickness was $45 \pm 5 \mu \mathrm{m},\left[\mathrm{Na}^{+}\right]$was $115 \pm 4 \mathrm{mM}$, $\left[\mathrm{Cl}^{-}\right]$was $140 \pm 5 \mathrm{mM}$, and $\mathrm{pH}$ was $6.95 \pm 0.05$. Similar ASL tonicity and $\mathrm{pH}$ were found in cystic fibrosis (CFTR-null) mice. In freshly harvested human bronchi, ASL thickness was $55 \pm 5 \mu \mathrm{m},\left[\mathrm{Na}^{+}\right]$was $103 \pm 3 \mathrm{mM},\left[\mathrm{Cl}^{-}\right]$was $92 \pm 4 \mathrm{mM}$, and $\mathrm{pH}$ was $6.78 \pm 0.2$. These results establish by a noninvasive approach the key properties of the ASL and provide direct evidence that the ASL is approximately isotonic and not saltier in cystic fibrosis.
\end{abstract}

J. Clin. Invest. 107:317-324 (2001).

\section{Introduction}

The airway-surface liquid (ASL) is the thin layer of aqueous fluid that coats the airway mucosal surface. The ASL contains salts and a variety of macromolecules to carry out transport, detoxification and anti-infectious functions (1). The composition and dynamics of the ASL are thought to play a key role in the physiology of asthma, bronchitis, and the most common genetic disorder, cystic fibrosis $(2,3)$. Two opposing theories have been proposed to explain the lung pathophysiology in cystic fibrosis. The "low salt" theory postulates that the normally low ASL salt concentration becomes high in cystic fibrosis, inhibiting the activity of endogenous antimicrobials such as defensins (4-6). The "low volume" theory postulates that avid salt absorption in cystic fibrosis creates a viscous, dehydrated mucus that promotes infection (7). ASL salt concentration is always near isotonic in the low volume theory. Several lines of indirect evidence have been reported to support each theory (reviewed in refs. 8, 9). An accurate description of ASL properties is critical to the rational design of therapies for cystic fibrosis and other airway diseases. The low salt theory predicts the efficacy of maneuvers that lower ASL salt in cystic fibrosis, whereas the low volume theory favors maneuvers that hydrate the ASL.

In cell-culture models, salt concentrations of 40-180 $\mathrm{mM}$ have been reported in different cell types studied by different methods $(4,5,7,10,11)$. In the in vivo tra- chea, salt concentrations of $45-138 \mathrm{mM}$ have been found using filter paper- and micropipette-sampling methods (12-18). These invasive methods have been criticized because the sampled volumes are generally much greater than the fluid volume contained in the normally less than $80-\mu \mathrm{m}$-thick ASL $(3,8,9,18)$. Theoretically, the ASL could be hypotonic, isotonic, or hypertonic. A hypotonic ASL would require high concentrations of as yet unidentified osmolytes in the ASL and/or the action of surface tension or other surface phenomena. A near-isotonic ASL is predicted for a highly waterpermeable epithelium in which salts constitute the majority of ASL osmolytes. A hypertonic ASL could in principle be generated if evaporative water losses exceed the ability of the airway epithelium to transport water into the ASL. Experimental measurement of ASL tonicity is required because there is no firm theoretical basis or consensus to choose among these possibilities. Another theory, based on the proposed bicarbonatetransporting role of CFTR and interactions with bicarbonate transporters $(19,20)$, is that an abnormality in ASL pH in cystic fibrosis might contribute to bacterial colonization and disease pathogenesis.

The purpose of this study was to develop and apply quantitative noninvasive methods to determine ASL thickness, sodium and chloride concentrations, and $\mathrm{pH}$ in cell-culture models and in vivo. The strategy was to stain the ASL with fluorescent indicators, to measure 
thickness using scanning confocal microscopy, and to measure sodium concentration, chloride concentration, and $\mathrm{pH}$ by ratio-imaging microscopy. This work required substantial technical innovations, including the construction of perfusion chambers and microscopy instrumentation, the development of surgical procedures to make measurements in the in vivo trachea, and the synthesis of cell-impermeable, dualwavelength sodium and chloride-selective fluorescent indicators with suitable sensitivity and optical properties. The results in cell-culture models, in vivo mouse trachea, and freshly excised human airways strongly support the conclusion that the ASL is near isotonic and not saltier in cystic fibrosis. The results have important implications regarding therapy in cystic fibrosis.

\section{Methods}

Perfusion chamber. A stainless steel perfusion chamber with a glass bottom was constructed to accommodate 24-mm-diameter cell-culture inserts. The chamber was held in a PDMI-2 microincubator (Harvard Apparatus, Holliston, Massachusetts, USA) maintained at $37^{\circ} \mathrm{C}$. Perfusates were preheated and delivered at $4 \mathrm{ml} /$ minute at specified pressure. Air $/ 5 \% \mathrm{CO}_{2}$ was passed through water $\left(\right.$ at $\left.37^{\circ} \mathrm{C}\right)$ in a Fisher-Milligan gas washer (Fisher Scientific Co., Pittsburgh, Pennsylvania, USA) to create the humidified atmosphere.

Cell culture. Bovine tracheal cells were cultured on collagen-coated semipermeable membranes (24-mm-diameter transparent polyethylenetetraphthalate membrane, $0.4-\mu \mathrm{m}$ pore size; Falcon, Becton Dickinson and Co., Plymouth, United Kingdom) at an air-liquid interface at $37^{\circ} \mathrm{C}$ in $5 \% \mathrm{CO}_{2} / 95 \%$ air until fully differentiated (21). Culture medium was changed every 2-4 days. Transepithelial resistance was measured using an epithelial volt-ohmmeter (World Precision Instruments, Sarasota, Florida, USA). Cultures were used 25-30 days after plating, at which time resistance was 300-600 $\Omega \cdot \mathrm{cm}^{2}$ and transepithelial potential difference was generally greater than $20 \mathrm{mV}$.

Labeling of ASL. Ten milligrams of fluorescent indicator was dispersed in $1 \mathrm{ml}$ of low-boiling perfluorocarbon (compound FC-72, boiling point $56^{\circ} \mathrm{C}$; $3 \mathrm{M}$ company, St. Paul, Minnesota, USA) using brief-probe sonication. Fifty microliters of the perfluorocarbon was added to the ASL 2-3 minutes before measurements. Alternately, after dispersion of indicator into the perfluorocarbon, the solvent was evaporated to obtain very fine solid particles that were sprayed onto the ASL 10 minutes before measurement. Alternately, $10-45 \mathrm{nl}$ of indicator in PBS was injected onto the ASL using a Nanoject-II microinjector (Drummond Scientific Co., Broomall, Pennsylvania, USA). After measurements, the dyes could be washed away from the ASL, indicating that they do not undergo significant endocytosis or cell adhesion. Also, the indicators showed homogeneous distributions on the ASL without accumulation or exclusion from surface mucus, which was present in patches in some cultures.
Microscopy. Fluorescence was measured using a Nipkow wheel-type confocal microscope (Leica Microsystems Inc., Buffalo, New York, USA, with confocal/coaxial module from Technical Instruments, Burlingame, California, USA) with photomultiplier detector and custom filter sets for quinolinium, tetramethylrhodamine, 2',7'-bis-(2-carboxyethyl)-5-(and-6)-carboxy fluorescein (BCECF), sodium-red and BODIPY-fl chromophores. Background signals were less than $1 \%$ except for quinolinium fluorescence, where background autofluorescence was at a maximum of $10 \%$ of the total signal (and subtracted). Fluorescence was detected using a $\times 40$ air objective lens (numerical aperture 0.65 , working distance $5 \mathrm{~mm}$ ) or a $\times 50$ ELWD objective lens (numerical aperture 0.55 , working distance $8 \mathrm{~mm}$ ) for ASL thickness measurements and a $\times 20$ extra-long working distance objective lens (numerical aperture 0.35 , working distance 20.5 $\mathrm{mm}$ ) for $\left[\mathrm{Na}^{+}\right],\left[\mathrm{Cl}^{-}\right]$, and $\mathrm{pH}$ measurements. The microscope fine focus was driven by a microstepper motor (12200 steps/revolution, 1400 steps/200 $\mu \mathrm{m}$; Compumotor Inc., Rohnert Park, California, USA). Motor control and signal detection were controlled by a custom-written LABVIEW software (National Instruments Corp., Austin, Texas, USA). ASL thickness was determined using a reconvolution technique based on the objective z-point spread function using custom-written software. The $z$-point spread function, measured for a thin, dry fluorophore layer $(<1 \mu \mathrm{m})$, was convoluted with square wave functions corresponding to different fluid depths. Measured z-scans (from at least three different spots on each culture) and computed z-scans for each thickness were compared to determine ASL depth. Thicknesses of standards consisting of specified solution volumes sandwiched between coverglasses were determined to better than $2-\mu \mathrm{m}$ accuracy.

Fluorescent indicators. The novel chloride indicator 6-phenyl- $N$-(6-carboxyhexyl) quinolinium was synthesized by heating 6-phenylquinolinium and 6-bromohexanoic acid (1:1.5 molar ratio) to $110^{\circ} \mathrm{C}$ for 4 hours. The resulting solid was washed with acetone overnight, filtered, and recrystallized from methanol. Dextran conjugates of 6-phenyl- $N$-(6-carboxyhexyl)quinolinium and 6-carboxytetramethyl rhodamine succinimidyl ester (Molecular Probes Inc., Eugene, Oregon, USA) were synthesized by reaction of the dyes with aminodextran (40,000 mol wt) (10 mol quinolinium/1.5 mol tetramethylrhodamine $/ 1 \mathrm{~mol}$ dextran) for 1 hour at $\mathrm{pH}$ 8.5 in $0.1 \mathrm{M} \mathrm{NaHCO}_{3}$ containing $5 \mathrm{mM}$ 1-ethyl-3(3-dimethylaminopropyl) carbodiimide and $5 \mathrm{mM}$ $N$-hydroxy succinimide. After reaction at room temperature for 1 hour, the mixture was dialyzed for 24 hours using 25,000-Da cut-off dialysis tubing against $0.1 \mathrm{~N} \mathrm{NaHCO}_{3}$ to remove unreacted dye and then against water for 36 hours at $4^{\circ} \mathrm{C}$ to remove salts. The dextran conjugate was lyophilized and stored at $4^{\circ} \mathrm{C}$ in a desiccator. Final quinolinium/tetramethylrhodamine/dextran molar-labeling ratio was 4.5:0.5:1.

The sodium indicator "sodium red" $(50 \mu \mathrm{g})(\mathrm{MPR}$ number 71351; sample provided by Molecular Probes 
Inc.) and BODIPY-fl $(30 \mu \mathrm{g})$ in $2 \%$ methanol/water was added to a $1 \%$ (vol/vol) suspension of $200-\mathrm{nm}$ diameter carboxyl latex beads (Polymer Laboratories Inc., Amherst, Massachusetts, USA) suspended in $4 \mathrm{ml}$ water. After shaking for 1 hour, beads were centrifuged at $14,000 \mathrm{~g}$ for 30 minutes, dispersed by brief sonication, and washed three times with water. The chromophores remained quantitatively immobilized on the beads during ASL measurements and for more than 2 months storage in water at $4^{\circ} \mathrm{C}$ in the dark. Measurements of $\mathrm{pH}$ were carried out using the dual-excitation wavelength $\mathrm{pH}$ indicator BCECF conjugated to dextran (Molecular Probes Inc.).

Calibration protocols. For chloride calibrations to equalize perfusate and ASL $\left[\mathrm{Cl}^{-}\right]$, cell-culture inserts were incubated in $100 \mathrm{mM} \mathrm{KCl} / \mathrm{KNO}_{3}, 38 \mathrm{mM}$ $\mathrm{NaCl} / \mathrm{NaNO}_{3}, 1 \mathrm{mM} \mathrm{CaCl}, 1 \mathrm{mM} \mathrm{MgCl} 2,2 \mathrm{mM}$ $\mathrm{Na}_{2} \mathrm{HPO}_{4}, 0.5 \mathrm{mM} \mathrm{KH}_{2} \mathrm{PO}_{4}$, and $\left[\mathrm{Cl}^{-}\right]$from 0 to 138 $\mathrm{mM}$ (with $\mathrm{NO}_{3}{ }^{-}$replacing $\mathrm{Cl}^{-}$). Solutions contained 10 $\mu \mathrm{M}$ nigericin, $10 \mu \mathrm{M}$ valinomycin, $5 \mu \mathrm{M}$ CCCP, $10 \mu \mathrm{M}$ monensin, and $20 \mu \mathrm{M}$ forskolin. Incubations were done for up to 12 hours at $37^{\circ} \mathrm{C}$. For sodium calibrations, the solutions contained $1 \mathrm{mM} \mathrm{CaCl}, 1 \mathrm{mM}$ $\mathrm{MgCl}_{2}, 20 \mathrm{mM}$ HEPES, $10 \mathrm{mM}$ glucose, $5.8 \mathrm{mM} \mathrm{KCl}$, $124 \mathrm{mM} \mathrm{NaCl} / \mathrm{choline}$ chloride, and $\left[\mathrm{Na}^{+}\right]$from 0 to $124 \mathrm{mM}$ (choline ${ }^{+}$replacing $\mathrm{Na}^{+}$). The ionophores listed above were used excluding valinomycin. For all buffers, $\mathrm{pH}$ was 7.40. For $\mathrm{pH}$ calibrations, the solutions contained $1 \mathrm{mM} \mathrm{CaCl}_{2}, 1 \mathrm{mM} \mathrm{MgSO}_{4}, 20 \mathrm{mM}$ HEPES, $10 \mathrm{mM}$ glucose, $110 \mathrm{mM} \mathrm{KCl}, 20 \mathrm{mM} \mathrm{NaCl}$, and the ionophores listed above with $\mathrm{pH}$ adjusted to 5.0-8.0 (in $0.5 \mathrm{pH}$ unit intervals). For experiments with bicarbonate-containing solutions, the perfusion buffer contained $1 \mathrm{mM} \mathrm{CaCl}_{2}, 1 \mathrm{mM} \mathrm{MgCl}_{2}, 25 \mathrm{mM}$ HEPES, 10 $\mathrm{mM}$ glucose, $25 \mathrm{mM} \mathrm{NaHCO} 3,5 \mathrm{mM} \mathrm{KCl}, 95 \mathrm{mM}$ $\mathrm{NaCl}$, bubbled with $5 \% \mathrm{CO}_{2} /$ air.

Measurements in intact trachea. Mice (25-35 g body weight) were anesthetized with pentobarbital (50 $\mathrm{mg} / \mathrm{kg}$, intraperitoneally). In some experiments, atropine $(1 \mathrm{mg} / \mathrm{kg})$ was given 10 minutes before anesthesia. Following a midline neck incision, $1-1.5 \mathrm{~cm}$ of trachea was bluntly isolated without vascular trauma. Two procedures were used to instill dye into the trachea and visualize indicator fluorescence; $50 \mu \mathrm{l}$ of indicator dispersed in perfluorocarbon was instilled into the trachea via the mouth using a 25 -gauge feeding needle. Alternately, a small window was cut into the anterior wall of the trachea just below the thyroid (width $2 \mathrm{~mm}$, length $5 \mathrm{~mm}$ ) (see Figure 6a). Through this window $5 \mu \mathrm{L}$ of dye dispersed in perfluorocarbon was added. The window was covered with transparent plastic wrap using tissue adhesive (Jorgensen Laboratories, Loveland, Colorado, USA). The mice breathed room air spontaneously. Fluorescence was detected using the $\times 20$ objective lens. Mice were sacrificed using an overdose of pentabarbital at the completion of the measurements. All animal protocols were approved by the University of California, San Francisco, Committee on Animal Research.
For measurements in human airways, freshly excised fragments of human main-stem bronchi were harvested from lungs. The whole lung with $3-5 \mathrm{~cm}$ of trachea intact was excised, the tracheal end was ligated, and tissues were transported to the laboratory in generally less than 2 hours in physiological saline on ice. Main-stem bronchi (cut to approximately $2 \mathrm{~cm}$ long, $1 \mathrm{~cm}$ wide, 2 $\mathrm{mm}$ thick) were dissected in a $100 \%$ humidified environment, placed over a wire mesh in a tissue-culture well with $\mathrm{HCO}_{3}{ }^{-}$-containing media bathing the serosa, and placed in the cell-culture incubator for 30 minutes. The bronchial fragment was then mounted using pins on a sponge soaked in $\mathrm{HCO}_{3}{ }^{-}$-containing buffer (on the serosal side) and held in the perfusion chamber with the mucosal side up at $37^{\circ} \mathrm{C}$ in a humidified $5 \%$ $\mathrm{CO}_{2} /$ air atmosphere. ASL was stained by adding $10 \mu \mathrm{l}$ of the indicator dispersed in perfluorocarbon. Fluorescence was detected using the $\times 50$ objective lens.

\section{Results}

A perfusion chamber was designed for use with an upright confocal microscope (Figure 1). Epithelial cell monolayers were grown on porous supports at an airliquid interface. The serosal surface of the cell layer was perfused with solutions of specified composition and the apical surface was exposed to humidified air (or 5\% $\mathrm{CO}_{2} / 95 \%$ air) at $37^{\circ} \mathrm{C}$. After staining the ASL with fluorescent dyes (using dispersed dye in volatile perfluorocarbon, dry powder, or microinjection), ASL fluorescence was detected by epifluorescence microscopy.

ASL thickness was measured by z-scanning confocal microscopy. Measurements in artificial solutions of known thickness demonstrated the determination of ASL thickness to better than $2-\mu \mathrm{m}$ accuracy in less than 5 seconds (Figure $2 \mathrm{a}$ ). Figure $2 \mathrm{~b}$ shows ASL thickness in cultures of bovine tracheal epithelial cells. ASL thickness was $21 \pm 4 \mu \mathrm{m}$ (SE, $n=10$ cultures) and uniform throughout the surface, in general agreement with pre-

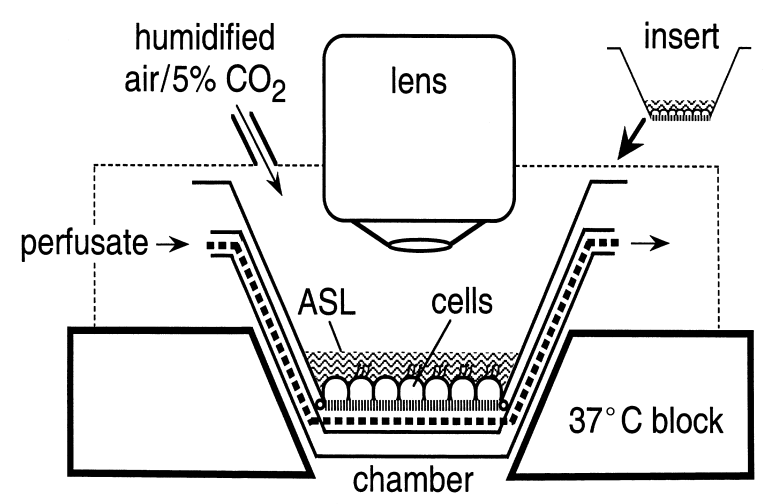

\section{Figure 1}

Schematic of the perfusion system for measurement of ASL properties in cell culture models. Epithelial cell monolayers cultured on porous supports were perfused at the serosal surface and exposed to a humidified $5 \% \mathrm{CO}_{2}$ atmosphere, at the mucosal surface. Temperature was maintained at $37^{\circ} \mathrm{C}$. ASL fluorescence was measured using a long working distance objective lens. 
Figure 2

Determination of ASL thickness by z-scanning confocal microscopy. (a) Fluorescence z-scans of layers of specified thickness containing $5 \mathrm{mg} / \mathrm{ml}$ tetramethylrhodaminedextran in PBS. (b) Scans of ASL stained with tetramethylrhodamine dextran. Where indicated, cells were exposed to dry air for 20 minutes or $0.2 \mathrm{mg}$ dry $\mathrm{NaCl}$ was added to the ASL. (c) Time course of ASL thickness in response to addition of $100 \mu \mathrm{l}$ of saline containing $100 \mu \mathrm{g}$ of tetramethylrhodamine dextran in the absence and presence of $10 \mu \mathrm{M}$ amiloride in the mucosal solution (mean $\pm \mathrm{SE}, n=3$ cultures). $\mathbf{a}$

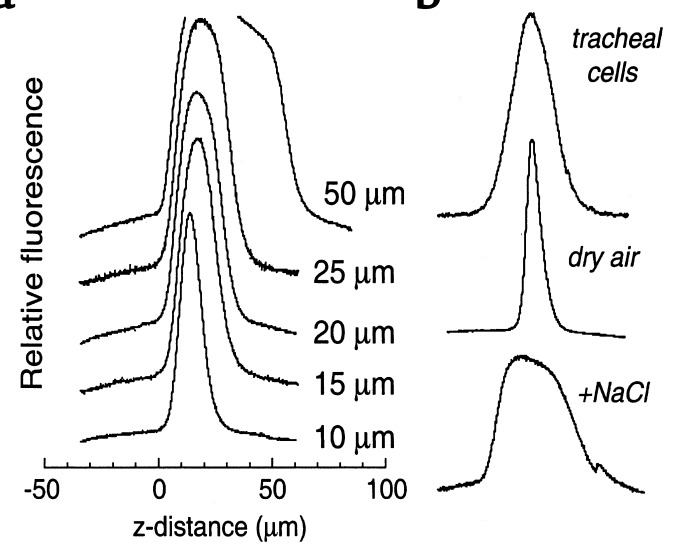

C

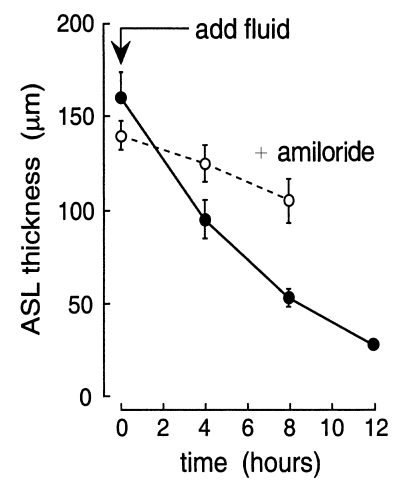

vious estimates $(7,18)$. ASL thickness remained constant over more than 1 hour of observation and was insensitive to perfusion pressure in the range of 5-25 $\mathrm{cm} \mathrm{H}_{2} \mathrm{O}$. ASL thickness decreased to $8 \mu \mathrm{m}$ when the humidified air was replaced by dry air, and increased rapidly upon addition of dry salt or mannitol to drive water influx osmotically (Figure $2 b$, bottom curves). Interestingly, ASL depth was not changed significantly by incubation of cells for 2 hours with amiloride (1 $\mathrm{mM})$, glibenclamide $(300 \mu \mathrm{M}), 4,4^{\prime}$-dinitrostilbene- $2,2^{\prime}$ disulfonic acid (DNDS; $100 \mu \mathrm{M})$, or 5-nitro-2-(3phenylpropylamino)benzoate (NPPB; $100 \mu \mathrm{M}$ ) (see Discussion). After increasing ASL thickness to approximately $150 \mu \mathrm{m}$ by addition of saline, active fluid absorption restored the original ASL thickness over an 8 -hour time course (Figure 2c). ASL absorption was markedly slowed by amiloride, indicating the involvement of an amiloride-sensitive sodium channel.

A dual-wavelength quinolinium-based fluorescent dextran was synthesized for measurement of ASL $\left[\mathrm{Cl}^{-}\right]$ (Figure 3a). The indicator emits $\mathrm{Cl}^{-}$-insensitive red fluorescence and $\mathrm{Cl}^{-}$-sensitive blue fluorescence so that ratio of red-to-blue fluorescence provides a quantitative measure of $\left[\mathrm{Cl}^{-}\right]$that does not depend on indicator concentration. In aqueous solutions, the red-to-blue fluorescence ratio increased linearly with $\left[\mathrm{Cl}^{-}\right]$(Figure $3 b)$ with a Stern-Volmer quenching constant of $13 \mathrm{M}^{-1}$. Indicator fluorescence and $\left[\mathrm{Cl}^{-}\right]$sensitivity were not affected by changes in $\mathrm{pH}$ (range $4-8), \mathrm{Na}^{+} / \mathrm{K}^{+}$concentrations $(0-150 \mathrm{mM})$, organic anions (e.g., lactate, citrate, $0-100 \mathrm{mM})$, or albumin $(0-10 \%)$.

ASL $\left[\mathrm{Cl}^{-}\right]$was determined from the red-to-blue fluorescence ratio of the indicator dissolved in the ASL. The fluorescence ratio was calibrated against $\left[\mathrm{Cl}^{-}\right]$by incubating the cell monolayers in a high- $\mathrm{K}^{+}$buffer containing different $\left[\mathrm{Cl}^{-}\right]$(nitrate replacing $\mathrm{Cl}^{-}$) and ionophores for 10-12 hours, at which time ionic equilibration was complete. The cell layers remained viable and ASL thickness remained in the range 20-25 $\mu \mathrm{m}$. Figure $3 \mathrm{c}$ shows that red-to-blue fluorescence ratios measured in the ASL were similar to those measured in aqueous solutions, indicating that the ASL does not contain substances that interfere with the indicator fluorescence. The similar in vivo and in vitro sensitivity of 6-phenyl- $N$-(6-carboxyhexyl)quinolinium fluorescence to $\left[\mathrm{Cl}^{-}\right]$is in agreement with the known physical chemistry of quinolinium-type chloride indicators (22). a

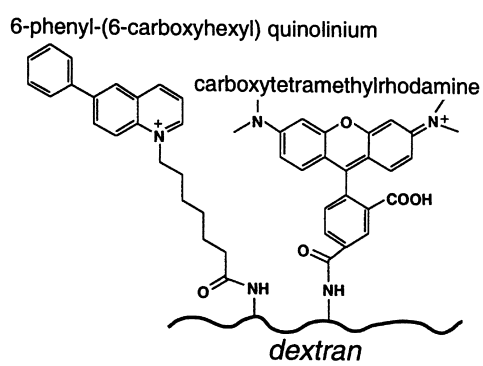

b

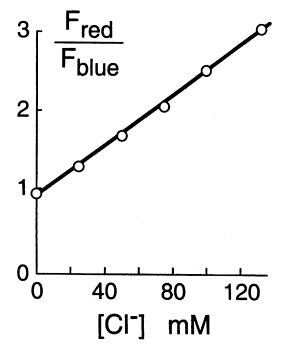

C

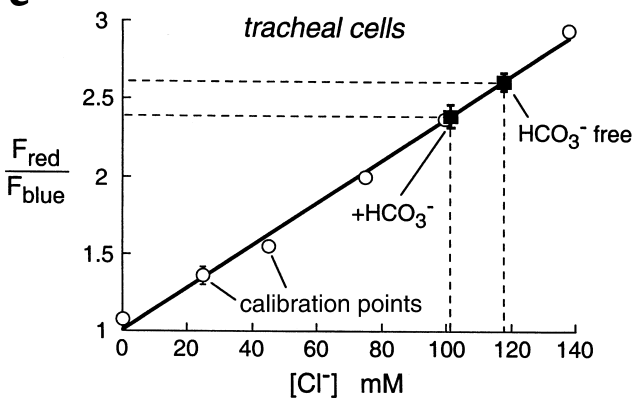

Figure 3

Chloride concentration in the ASL of well-differentiated tracheal epithelial cell cultures. (a) Fluorescent dextran was synthesized for determination of $\left[\mathrm{Cl}^{-}\right]$by ratio-imaging microscopy. Blue quinolinium ( $\mathrm{Cl}^{-}$-sensitive) and red tetramethylrhodamine $\left(\mathrm{Cl}^{-}\right.$-insensitive $)$chromophores were covalently conjugated to dextran. (b) Indicator red-to-blue fluorescence ratio versus $\left[\mathrm{Cl}^{-}\right]$in $\mathrm{PBS}_{\left(\mathrm{Cl}^{-}\right.}$replaced by $\left.\mathrm{NO}_{3}^{-}\right)$. (c) Red-toblue fluorescence ratio versus ASL $\left[\mathrm{Cl}^{-}\right]$measured using an ionophore calibration procedure to set $\mathrm{ASL}\left[\mathrm{Cl}^{-}\right]$(mean $\pm \mathrm{SE}$, three cultures for each $\left.\left[\mathrm{Cl}^{-}\right]\right)$. Also shown is $\mathrm{ASL}\left[\mathrm{Cl}^{-}\right]$measured in $\mathrm{HCO}_{3}^{-}$-free and $\mathrm{HCO}_{3}{ }^{-}$-containing solutions $(n=4$ cultures). 

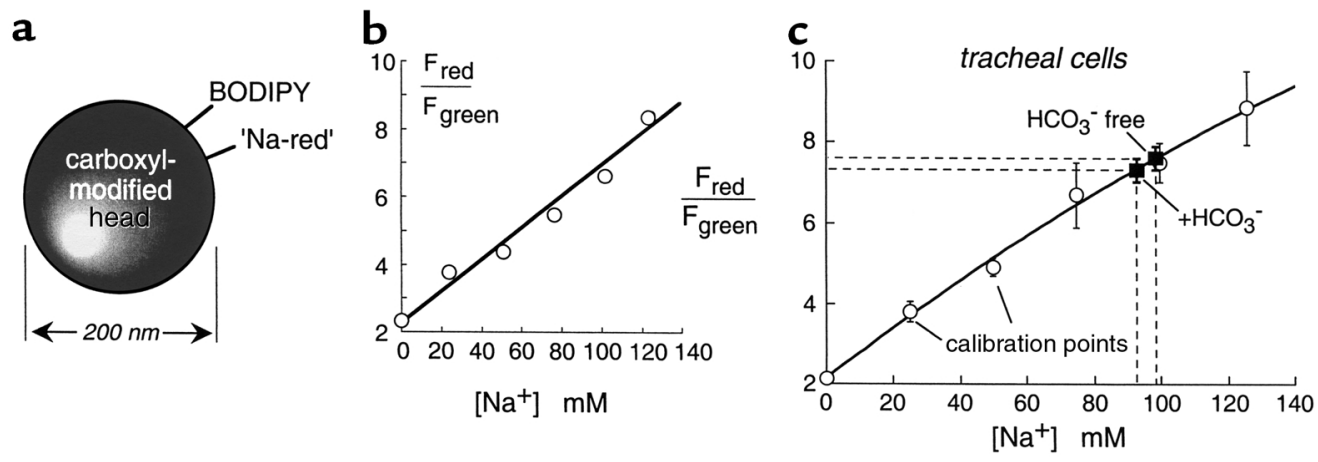

Figure 4

Sodium concentration in the ASL of well-differentiated tracheal epithelial cell cultures. (a) Fluorescent bead was used for determination of $\left[\mathrm{Na}^{+}\right]$. Sodium-red and green BODIPY-fl chromophores were immobilized on 200-nm-diameter polystyrene beads. (b) Bead red-togreen fluorescence ratio versus $\left[\mathrm{Na}^{+}\right]$in PBS $\left(\mathrm{Na}^{+}\right.$replaced by choline $\left.{ }^{+}\right)$. (c) Red-to-green fluorescence ratio versus $\mathrm{ASL}\left[\mathrm{Na}^{+}\right]$measured using an ionophore calibration procedure to set $\mathrm{ASL}\left[\mathrm{Na}^{+}\right]$(mean $\pm \mathrm{SE}$; three cultures for each $\left[\mathrm{Na}^{+}\right]$). Also shown is $\mathrm{ASL}\left[\mathrm{Na}^{+}\right]$ measured in $\mathrm{HCO}_{3}{ }^{-}$-free and $\mathrm{HCO}_{3}{ }^{-}$-containing solutions ( $n=4$ cultures).

ASL $\left[\mathrm{Cl}^{-}\right]$was $118 \pm 3 \mathrm{mM}$ in the nominal absence of $\mathrm{CO}_{2}$ and $101 \pm 2 \mathrm{mM}$ in the presence of $25 \mathrm{mM}$ bicarbonate in the perfusate ( $\mathrm{pH} 7.4$ ) and $5 \% \mathrm{CO}_{2}$ in the humidified atmosphere at the mucosal surface (Figure 3c). Similar values were obtained when the indicator was introduced using dry powder or microinjection of aqueous solutions of the dextran.

For ratiometric determination of ASL $\left[\mathrm{Na}^{+}\right]$, a red fluorescent sodium indicator, referred to as sodium-red, was immobilized on carboxyl latex beads (200-nm diameter) together with a $\left[\mathrm{Na}^{+}\right]$-insensitive green chromophore (BODIPY-fl) (Figure 4a). Bead red-to-green fluorescence ratio increased with $\left[\mathrm{Na}^{+}\right]$(Figure $4 \mathrm{~b}$ ) and was insensitive to $\mathrm{pH}(4-8),\left[\mathrm{K}^{+}\right](0-300 \mathrm{mM})$, and organic solutes. As described for $\mathrm{Cl}^{-}$, an ionophore calibration procedure was performed to relate bead red-togreen fluorescence ratios to ASL $\left[\mathrm{Na}^{+}\right]$(Figure 4c). ASL $\left[\mathrm{Na}^{+}\right]$in bovine tracheal epithelial cells was $97 \pm 5 \mathrm{mM}$ under nominally $\mathrm{CO}_{2}$-free conditions and $92 \pm 5 \mathrm{mM}$ in the presence of $\mathrm{CO}_{2}$ (Figure 4c). After incubation for 2 hours with the CFTR blockers glibenclamide $(300 \mu \mathrm{M})$ or NPPB $(100 \mu \mathrm{M})$, ASL $\left[\mathrm{Na}^{+}\right]$was $100 \pm 8 \mathrm{mM}(n=3)$ and $115 \pm 11 \mathrm{mM}(n=4)$, respectively, not significantly different from that in untreated cultures.

Measurements of ASL $\mathrm{pH}$ were carried out using the cell-impermeable $\mathrm{pH}$ indicator BCECF-dextran. BCECF fluorescence is very sensitive to $\mathrm{pH}$ in the range of 6.5 to 7.5 , which is ideal for ASL $\mathrm{pH}$ measurements. Ratio imaging was done at 440- and 490$\mathrm{nm}$ excitation wavelengths with detection at $535 \mathrm{~nm}$. Figure 5 shows $\mathrm{pH}$ calibrations of $\mathrm{F}_{490} / \mathrm{F}_{440}$ versus $\mathrm{pH}$ in solution and in the ASL. The $\mathrm{p} K_{\mathrm{a}}$ of BCECF-dextran was 7.0 in solution and in the ASL. ASL $\mathrm{pH}$ was $6.84 \pm 0.05(n=4)$ in the nominal absence of $\mathrm{CO}_{2}$ and $6.94 \pm 0.03(n=4)$ in the presence of $25 \mathrm{mM}$ bicarbonate in the perfusate $(\mathrm{pH} 7.4)$ and $5 \% \mathrm{CO}_{2}$ in the humidified atmosphere. There was no significant effect of glibenclamide or NPPB on ASL $\mathrm{pH}$.

Although cell-culture models have been used widely to study ASL properties, there are concerns that culture models do not accurately mimic the in vivo airways and are difficult to reproduce in their precise cell makeup, transepithelial resistance, and transport properties. Additionally, cell cultures are not exposed to the timevarying air flows, moisture content, and $\mathrm{O}_{2} / \mathrm{CO}_{2}$ composition sensed by the tracheal mucosa in vivo.

We applied the techniques developed above to the in vivo trachea in anesthetized mice. A small window was cut in the mouse trachea, fluorescent dyes were introduced using perfluorocarbon or dry powders, and the window was sealed with transparent plastic (Figure 6a, left). In a second approach suitable for the bright-sodi$\mathrm{um}$ and $\mathrm{pH}$ indicators, the fluorescent probe was introduced into the trachea via the mouth using a feeding needle, and fluorescence was measured through the intact translucent tracheal wall (Figure $6 a$, right). The mice breathed spontaneously in both

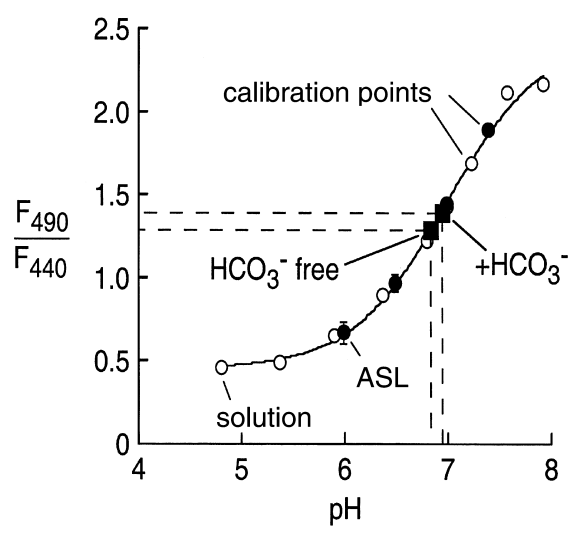

Figure 5

ASL pH in well-differentiated bovine tracheal epithelial cell cultures. Ratios of BCECF-dextran fluorescence at 490 and $440 \mathrm{~nm}$ are measured in buffers of specified $\mathrm{pH}$. Open circles are calibration points for cell-free solution measurements, and filled circles are for calibration measurements (high- $\mathrm{K}^{+}$solution containing ionophores) in ASL. Also shown is $\mathrm{ASL} \mathrm{pH}$ measured in physiological $\mathrm{HCO}_{3}{ }^{-}$-free and $\mathrm{HCO}_{3}{ }^{-}$-containing solutions ( $n=4$ cultures). 

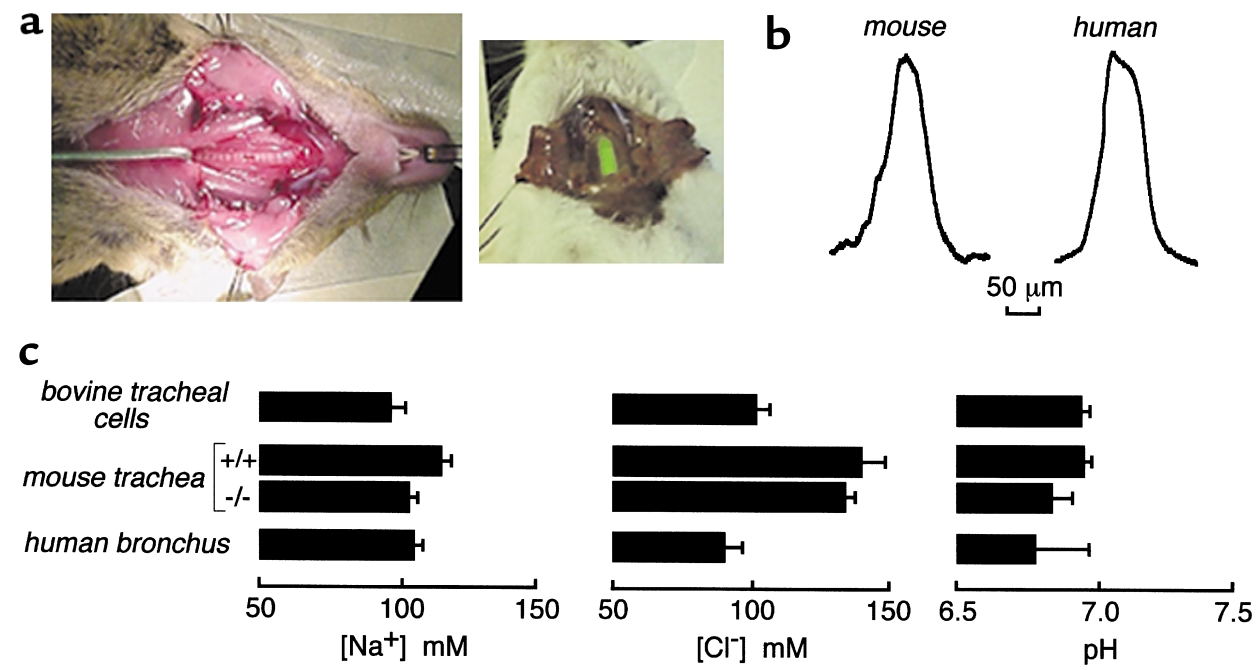

\section{Figure 6}

ASL properties in the in vivo mouse trachea and freshly excised fragments of human bronchi. (a) Mouse preparation for measurement of ASL thickness and salt concentration showing the exposed trachea in which a rectangular window was cut (left). After dye instillation, the window was sealed with transparent plastic for fluorescence measurements. Brighter dyes could be instilled into the trachea via a feeding needle and fluorescence measured through the translucent tracheal wall (right). (b) ASL thickness determined in mouse trachea (left) and human freshly excised bronchi (right) using z-scanning confocal microscopy in which the ASL was stained with tetramethylrhodamine-dextran. See text for averaged values. (c) Summary of ASL sodium and chloride concentrations and $\mathrm{pH}$ for wild-type (SE, $n=6)$ and CF mice (SE, $n=3$ ) and human bronchi (SE, $n=3$ ). For comparison, results from bovine tracheal cell cultures (from Figures 2-5) are given. (Note that mouse plasma osmolality is 315-325 mOsm and osmolality for media bathing the human bronchi and cell cultures is $290-296$ mOsm.)

approaches. Care was taken during surgery and indicator addition to minimize perturb-ing the trachea. There was no apparent activation of tracheal secretion in approximately $70 \%$ of untreated mice and more than $90 \%$ of atropine-treated mice. In addition, ASL thickness and salt concentrations remained stable for more than 1 hour, and $\left[\mathrm{Na}^{+}\right]$, which was measured both through the intact tracheal wall and the window, was not affected by creating the window.

Figure $6 \mathrm{~b}$ (left) shows a representative determination of ASL thickness in mouse trachea using z-scanning confocal microscopy. Average ASL thickness was $45 \pm 5 \mu \mathrm{m}(n=4)$, which is in the range of $35-100 \mu \mathrm{m}$ estimated in pig, ferret, cow, and human trachea $(3,10)$. Figure $6 \mathrm{c}$ summarizes ASL $\left[\mathrm{Cl}^{-}\right],\left[\mathrm{Na}^{+}\right]$, and $\mathrm{pH}$ for normal and cystic fibrosis (CF) mouse trachea in vivo, freshly excised human bronchi, and bovine tracheal cell cultures. ASL $\left[\mathrm{Cl}^{-}\right]$was $140 \pm 5 \mathrm{mM}$ in the trachea of wild-type mice and similar in CF mice. ASL $\left[\mathrm{Na}^{+}\right]$was $115 \pm 4$ in wild-type mice and $105 \pm 3$ $\mathrm{mM}$ in CF mice. $\mathrm{K}^{+}$is probably the major unmeasured cation. ASL pH was $6.95 \pm 0.03$ in wild-type mice, not significantly different from $6.84 \pm 0.07$ in $\mathrm{CF}$ mice. Computing a $\left[\mathrm{HCO}_{3}^{-}\right]$of $8 \mathrm{mM}$ based on the ASL pH of 6.95 , the measured $\left[\mathrm{Cl}^{-}\right]$of $140 \mathrm{mM}$ predicts an osmolality of $296 \mathrm{mOsm}$ for mouse ASL, which is similar to that of 311-325 mOsm for mouse plasma. In excised bronchial fragments from three human subjects who did not have CF, ASL thickness was $55 \pm 5 \mu \mathrm{m},\left[\mathrm{Na}^{+}\right]$was $103 \pm 3 \mathrm{mM},\left[\mathrm{Cl}^{-}\right]$was $92 \pm$ $4 \mathrm{mM}$, and $\mathrm{pH}$ was $6.78 \pm 0.2$.

\section{Discussion}

Our results provide direct evidence that the ASL salt concentration is approximately isotonic in airway cellculture models, in the mouse trachea in vivo, and in freshly excised human bronchi. This conclusion was insensitive to methodological details, such as the different methods used to stain the ASL, the presence of bicarbonate, and other factors. Although CF mice are imperfect models of airway disease and acceptable human CF airway specimens were not available, the near isotonicity of ASL in normal cell cultures and mouse and human airways makes it very unlikely that ASL salt concentration could be higher in CF. A near isotonic ASL is consistent with the inability of the highly water-permeable airway epithelium to sustain an osmotic gradient $(23,24)$ and with evidence that ciliary surface-tension effects do not create an osmotic imbalance (7). Attempts to decrease ASL tonicity are thus unlikely to be of benefit in the treatment of CF.

An interesting observation was the insensitivity of ASL thickness in cell-culture models to ion substitution, ionophores, perfusion pressure, and inhibitors of membrane transport. Substantial changes in ASL thickness were found only for the gross maneuvers of rapid evaporation (dry atmosphere) or osmotic stress (salt addition to the ASL). Although the lower ASL thickness in cell-culture models compared with intact trachea casts further doubt on the utility of cell-culture models to study ASL properties, it is interesting to speculate about the reasons for the constancy of ASL thickness. The lack of effect of transport inhibitors 
makes regulated membrane transport unlikely. Furthermore, it is difficult to understand how an epithelial cell can sense the location of the ASL surface. We speculate that surface tension or other phenomena, although insufficient to create an osmotic imbalance, play a role in setting ASL depth. The challenge will be to define quantitatively the driving forces that establish ASL thickness and salt concentration, ultimately to establish a mathematical model with predictive value. ASL $\mathrm{pH}$ was in the range of 6.8-7.0 in the various model systems and not different in the CF mice or in airway cell cultures treated with CFTR inhibitors. Previously, ASL $\mathrm{pH}$ in porcine bronchial ASL was estimated indirectly to be in the range of 7.33-7.45 from bicarbonate measurements made on submucosal gland secretions (25). In ferret trachea in vitro, ASL pH was measured as $6.84 \pm 0.03$ using a catheter-tipped $\mathrm{pH}$ electrode implanted in a cannula held close to the airway epithelium (26). To our knowledge, the study here reports the first direct noninvasive measurements of ASL $\mathrm{pH}$. The similar values of ASL $\mathrm{pH}$ in CF mice and after CFTR inhibition in bovine tracheal epithelial cells suggest that abnormalities in ASL $\mathrm{pH}$ regulation are unlikely to contribute to the pathogenesis of CF. Further work is needed to identify the membrane transporters and define the electrochemical driving forces that regulate ASL $\mathrm{pH}$.

The ratiometric fluorescence measurements of ASL $\left[\mathrm{Na}^{+}\right],[\mathrm{Cl}-]$, and $\mathrm{pH}$ do not provide information about osmolality, $\left[\mathrm{K}^{+}\right]$, or other unmeasured cations and anions. Without direct information about ASL osmolality and $\left[\mathrm{K}^{+}\right]$, it is difficult to speculate about the amount and nature of remaining ASL solutes. Fluorescence methods are under development to measure these important ASL parameters.

A variety of complementary techniques have been used to measure ASL composition in mice and large animals, including analysis of fluid collected by filter paper $(12-15)$ and microcapillary tubes $(16,17)$ and, very recently, direct sensing of $\left[\mathrm{Cl}^{-}\right]$using a solid-state electrode (27). Each of these methods requires direct mechanical contact with the ASL, introducing potential artifacts from stimulation of surface and gland fluid secretion and collection of intracellular and interstitial fluids by capillary suction $(3,8,28)$. ASL composition in cell-culture models has also been estimated by cryoprobe/x-ray microanalysis $(29,30)$ and radio-tracer methods (5), which are also invasive and provide only single time-point measurements. Our approach here involving fluorescent dye staining of ASL and microscopy permits continuous quantitative measurements of ASL properties with minimal mechanical perturbation of the ASL. The robustness of the results in different systems using different dye addition and sample preparation methods supports the validity of our methods.

A number of significant technical developments were required to measure ASL depth and salt concentration in culture models and in vivo. Brightly fluorescent dual- wavelength chloride and sodium indicators were required that were membrane impermeable, nontoxic, and sensitive in the range from 0 to more than $150 \mathrm{mM}$ $\left[\mathrm{Na}^{+}\right]$and $\left[\mathrm{Cl}^{-}\right]$. Based on our work on halide-sensitive fluorescent indictors, the 6-phenylquinolinium chromophore was chosen after screening a number of quinolinium-type chromophores. Synthetic procedures were developed to generate a dextran conjugate containing 6-phenyl- $N$-(6-carboxyhexyl)quinolinium and the chloride-insensitive chromophore tetramethylrhodamine. The dextran conjugate was suitable for ratiometric measurements of chloride concentration in the required concentration range and was insensitive to changes in $\mathrm{pH}$ and to other potential interfering substances. The dual-wavelength sodium indicator used a new chromophore synthesized by Molecular Probes Inc. as a membrane-permeable mitochondrial $\left[\mathrm{Na}^{+}\right]$indicator. Procedures were developed to immobilize the indicator, together with the reference BODIPY-fl chromophore, on small beads that could be readily added to the ASL. The ratiometric sodium indicator had excellent brightness and was sodium selective. Another key technical development was the rapid z-scanning confocal microscopy to give micron-resolution accuracy in the determination of ASL thickness. Finally, measurement of ASL properties in the in vivo trachea required the development of minimally invasive surgical procedures to instill the fluorescent dyes and, if necessary, to expose the posterior tracheal wall for direct visualization. We felt that closure of the tracheal window and spontaneous breathing was important in order to measure ASL properties under near physiological conditions.

The staining of ASL by engineered fluorescent indicators provides a noninvasive approach to monitor ASL properties continuously in vivo and without the uncertainties associated with filter paper- or capillary-sampling methods. In vivo measurements in larger animals and human subjects should be feasible using fiberoptic bronchoscopy with fluorescence detection. The generally assumed role of the ASL in genetic and acquired diseases of the airways such as asthma should now be amenable to direct experimental verification.

\section{Acknowledgments}

This work was supported by grants HL-60288, HL59198, DK-35124, and DK-43840 from the NIH and RDP grant R613 from the National Cystic Fibrosis Foundation. We thank L.J.V. Galietta for helpful discussions and electrophysiological measurements, J.H. Widdicombe and the NIH CF SCOR cell culture core for providing cultures of bovine tracheal epithelial cells, and Zhenjun Diwu at Molecular Probes Inc. for synthesis of sodium red.

\footnotetext{
1. Welsh, M.J. 1987. Electrolyte transport by airway epithelia. Physiol. Rev. 67:1143-1184.

2. Boucher, R.C. 1994. Human airway ion transport (Part 1). Am. J. Respir. Crit. Care Med. 150:271-281.

3. Pilewski, J.M., and Frizzell, R.A. 1999. Role of CFTR in airway disease. Physiol. Rev. 79:S215-S255.

4. Smith, J.J., Travis, S.M., Greenberg, E.P., and Welsh, M.J. 1996. Cystic
} 
fibrosis airway epithelia fail to kill bacteria because of abnormal airway surface fluid. Cell. 85:229-236

5. Zabner, J., Smith, J.J., Karp, P.H., Widdicombe, J.H., and Welsh, M.J. 1998. Loss of CFTR chloride channels alters salt absorption by cystic fibrosis airway epithelia in vitro. Mol. Cell. 2:397-403.

6. Quinton, P.M. 1994. Viscosity vs. composition in airway pathology. Am. J. Respir. Crit. Care Med. 149:6-7.

7. Matsui, H., et al. 1998. Evidence for periciliary liquid layer depletion, not abnormal ion composition, in the pathogenesis of cystic fibrosis airway disease. Cell. 95:1005-1015.

8. Wine, J.J. 1999. The genesis of cystic fibrosis lung disease. J. Clin. Invest. 103:309-312.

9. Boucher, R.C. 1999. Molecular insights into the physiology of the 'thin film' of airway surface liquid. J. Physiol. 516:631-638.

10. Widdicombe, J.H., Bastacky, S.J., Wu, D.X., and Lee, C.Y. 1997. Regulation of depth and composition of airway surface liquid. Eur. Respir. J. 10:2892-2897.

11. McCray, P.B., Jr., Zabner, J., Jia, H.P., Welsh, M.J., and Thorne, P.S. 1999. Efficient killing of inhaled bacteria in $\triangle F 508$ mice: role of airway surface liquid composition. Am. J. Physiol. 277:L183-L190.

12. Knowles, M.R., et al. 1997. Ion composition of airway surface liquid of patients with cystic fibrosis as compared with normal and disease-control subjects. J. Clin. Invest. 100:2588-2595.

13. Hull, J., Skinner, W., Robertson, C., and Phelan, P. 1998. Elemental content of airway surface liquid from infants with cystic fibrosis. Am. $J$ Respir. Crit. Care Med. 157:10-14.

14. Zhang, Y., and Engelhardt, J.F. 1999. Airway surface liquid volume and $\mathrm{Cl}$ content in cystic fibrosis and normal bronchial xenografts. Am. J. Physiol. 276:C469-C476.

15. Joris, L., Dab, I., and Quinton, P.M. 1993. Elemental composition of human airway surface fluid in healthy and diseased airways. Am. Rev. Respir. Dis. 148:1633-1637.

16. Govindaraju, K., Cowley, E.A., Eidelman, D.H., and Lloyd, D.K. 1997. Microanalysis of lung airway surface fluid by capillary electrophoresis with conductivity detection. Anal. Chem. 69:2793-2797.

17. Cowley, E.A., Govindaraju, K., Guilbault, C., Radzioch, D., and Eidel- man, D.H. 2000. Airway surface liquid composition in mice. Am. J. Physiol. 278:L1213-L1220.

18. Wu, D.X., et al. 1998. Regulation of the depth of surface liquid in bovine trachea. Am. J. Physiol. 274:L388-L395.

19. Min, G.L., et al. 1999. Regulation of $\mathrm{Cl}^{-} / \mathrm{HCO}_{3}{ }^{-}$exchange by cystic fibrosis transmembrane conductance regulator expressed in NIH 3T3 and HEK 293 cells. J. Biol. Chem. 274:3414-3421.

20. Smith, J.J., and Welsh, M.J. 1992. cAMP stimulated bicarbonate secretion across normal, but not cystic fibrosis airway epithelia. J. Clin. Invest. 89: $1148-1153$

21. Uyekubo, S.N., et al. 1998. cAMP-dependent absorption of chloride across airway epithelium. Am. J. Physiol. 275:L1219-L1227.

22. Verkman, A.S. 1990. Development and biological applications of chloride-sensitive fluorescent indicators. Am. J. Physiol. 25:C375-C388.

23. Farinas, J., Kneen, M., Moore, M., and Verkman, A.S. 1997. Plasma membrane water permeability of cultured cells and epithelia measured by light microscopy with spatial filtering. J. Gen. Physiol. 110:283-296.

24. Matsui, H., Davis, C.W., Tarran, R., and Boucher, R.C. 2000. Osmotic water permeability of cultured, well-differentiated normal and cystic fibrosis airway epithelia. J. Clin. Invest. 105:1419-1427.

25. Ballard, S.T., Trout, L., Bebok, Z., Sorscher, E.J., and Crews, A. 1999. CFTR involvement in chloride, bicarbonate, and liquid secretion by airway submucosal glands. Am. J. Physiol. 277:L694-L699.

26. Kyle, H., Ward, J.P., and Widdicombe, J.G. 1990. Control of $\mathrm{pH}$ of airway surface liquid in the ferret trachea in vitro. J. Appl. Physiol. 68:138-140.

27. Caldwell, R.A., et al. 2000. In vivo airway surface liquid [ $\left.\mathrm{Cl}^{-}\right]$in rabbits, monkeys, and humans measured with miniaturized solid-state $\mathrm{Cl}^{-}$electrodes. Pediatr. Pulmonol. 30:201. (Abstr.)

28. Erjefalt, I., and Persson, C.G. 1990. On the use of absorbing discs to sample mucosal surface liquids. Clin. Exp. Allergy. 20:193-197.

29. Baconnais, S., et al. 1999. Ion composition and rheology of airway liquid from cystic fibrosis fetal tracheal xenografts. Am. J. Respir. Cell Mol. Biol. 20:605-611.

30. Baconnais, S., et al. 1998. X-ray microanalysis of native airway surface liquid collected by cryotechnique. J. Microsc. 191:311-319. 